\title{
"Assessment of Heavy Metal Pollution in Soil of Chattogram Hill Tracts, Bangladesh and Concomitant Health Risk"
}

\section{Troyee Barua ( $\sim$ troyeebarua@gmail.com )}

Chittagong University of Engineering and Technology https://orcid.org/0000-0003-2322-6902

AKM Saiful Islam Bhuian

Bangladesh Atomic Energy Commission

\section{Mayeen Uddin Khandaker}

Sunway University

Nipa Deb

Bangladesh Atomic Energy Commission

\section{Shahadat Hossain}

Bangladesh Atomic Energy Commission

\section{Md. Abdur Rashid}

Chittagong University of Engineering and Technology

\section{Research Article}

Keywords: Chattogram Hill Tracts, soil pollution quantification, enrichment factors, Hierarchical cluster analysis, Ecological risk, Carcinogenic, Non-carcinogenic risk

Posted Date: March 18th, 2021

DOI: https://doi.org/10.21203/rs.3.rs-320812/v1

License: (c) (1) This work is licensed under a Creative Commons Attribution 4.0 International License.

Read Full License 


\title{
Assessment of heavy metal pollution in soil of Chattogram Hill Tracts,
}

\section{Bangladesh and concomitant health risk}

\author{
Troyee Barua ${ }^{1, *}$, AKM Saiful Islam Bhuian², Mayeen Uddin Khandaker ${ }^{3}$, Md. Abdur Rashid ${ }^{1}$, Nipa Deb², \\ Shahadat Hossain ${ }^{2}$
}

${ }^{1}$ Department of Physics, Chittagong University of Engineering and Technology, Chattogram -4349, Bangladesh ${ }^{2}$ Atomic Energy Centre, Chattogram, Bangladesh Atomic Energy Commission, Chattogram -4209, Bangladesh

${ }^{3}$ Centre for Biomedical Physics, School of Healthcare and Medical Sciences, Sunway University, 47500 Bandar Sunway, Selangor, Malaysia (1) 10 (1)

\section{Troyee Barua}

4 Department of Physics

5 Chittagong University of Engineering and Technology,

6 Chattogram 4349, Bangladesh

7 Email: troyeebarua@gmail.com

38 Tel: +8801813275159 


\title{
Bangladesh and concomitant health risk
}

Troyee Barua ${ }^{1, *}$, AKM Saiful Islam Bhuian², Mayeen Uddin Khandaker ${ }^{3}$, Md. Abdur Rashid ${ }^{1}$, Nipa Deb ${ }^{2}$, Shahadat Hossain ${ }^{2}$

\begin{abstract}
${ }^{1}$ Department of Physics, Chittagong University of Engineering and Technology, Chattogram -4349, Bangladesh ${ }^{2}$ Atomic Energy Centre, Chattogram, Bangladesh Atomic Energy Commission, Chattogram -4209, Bangladesh ${ }^{3}$ Centre for Biomedical Physics, School of Healthcare and Medical Sciences, Sunway University, 47500 Bandar Sunway, Selangor, Malaysia
\end{abstract}

\section{Abstract}

The increased human population and associated activities may create a risk in the ecological balance of Chattogram Hill Tracts (CHT), Bangladesh via contamination of soil with toxic heavy metals. Thus, the present study was conducted to assess the concentration of heavy metals (Lead, Cadmium, Copper, Zinc, Iron, Manganese, Chromium and Nickel) in forest soils of the CHT area by using an atomic absorption spectrometer. The degree of contamination of soil was evaluated by five indices: geo-accumulation index $\left(\mathrm{I}_{\mathrm{geo}}\right)$, enrichment factor $(\mathrm{EF})$, contamination factor (CF), pollution load index (PLI) and potential ecological risk index (PERI). According to these criteria, these soils can be classified as moderately contaminated with some metals. Furthermore, the identification of pollution sources based on principal component analysis and hierarchical cluster analysis have revealed that all analyzed metals are anthropogenic except $\mathrm{Fe}$. Calculated hazard index $>1$ indicates the possibility of noncarcinogenic effect due to higher value of Fe. Carcinogenic risks through the ingestion, inhalation and dermal pathway for carcinogenic elements ( $\mathrm{Pb}, \mathrm{Cd}, \mathrm{Cr}$, and $\mathrm{Ni}$ ) shows a nonsignificant risk $\left(\mathrm{CR}<10^{-6}\right)$ for both children and adults living in the studied area.

Measured data may help the policymakers to reduce the potential effects of soil contamination on eco-environment and human health.

Keywords: Chattogram Hill Tracts, soil pollution quantification, enrichment factors, Hierarchical cluster analysis, Ecological risk, Carcinogenic and Non-carcinogenic risk.

\section{Introduction}

Due to their potential toxicity and non-biodegradability, heavy metals (HMs) are recognized as a major inorganic pollutant for ecological and health concern, hence pose a non-negligible threat to living things (Ayangbenro and Babalola, 2017). All metals in the biosphere, regardless of essential and non-essential ones, find their ultimate 
ways to soil following the life-cycle of living beings and the natural cycle of non-living things. As a result, the overall metals cycle in nature is mediated by soil (Gbadamosi et al., 2018). One of the main ways of soil pollution by inorganic pollutants is via the man-made/anthropogenic/artificial activities including the exploration and extraction of mineral resources from earth crusts. Consequently, the metals available in the ecosystem can be easily transferred to food chains via geo-accumulation and bioaccumulation process, finally causes a greater risk to human health (Pejman et al., 2015).

The Chattogram Hill Tracts has been suggested as one of the most diverting regions of Bangladesh. The land area of CHT has been classified as reserve forests (> 394,300 ha), shifting cultivation (> 905,000 ha), and unclassed (the remaining area) (Ahammad and Stacey, 2016). A total of 11 Ethnic groups of people live in this region (UNICEF Bangladesh, 2019). Due to the increasing human population in CHT area day-by-day (i.e., the migration of peoples from other places of Bangladesh to Rangamati, Khagrachari and Bandarban), it sees a large scale anthropogenic activities including deforestation. The main cause of deforestation is the shifting of traditional cultivation (Jhum cultivation), and unplanned development activities (Ahammad and Stacey, 2016; Osman, 2014). The quality of forest soil is naturally acidic, has multi-layer with forest floor, hemi-organic and mineral layers (Hassan et al., 2017; Osman, 2014). The soils of CHT are mostly sandy (37 to 67\%) and the rest of them are silt and clay [6]. Though the soils of CHT is not suitable for agriculture, frequent use of the same land towards biomass production reduces soil fertility and increase the level of toxic metals and various pollutants (Biswas et al., 2010). Also, contamination of soil including metal concentration is hampered by some other factors such as soil properties, such as $\mathrm{pH}$, organic matter content, minerals, cation exchange capacity of the soil phase, balancing with other metal ions etc. (Alfaro et al., 2015; Perković et al., 2017).

The higher concentration of heavy metals represents the negative influence on the forest ecosystem (Wahab et al., 2020). The high concentration of some metals such as $\mathrm{Cu}, \mathrm{Zn}, \mathrm{Ni}, \mathrm{Mn}, \mathrm{Co}, \mathrm{Se}, \mathrm{Ag}, \mathrm{Sb}$, and notably $\mathrm{Cr}$ and $\mathrm{Ti}$ pose toxic effects to human and animal health via the food chain (Perković et al., 2017). Based on the United States Environmental Protection Agency (USEPA, 2000) report, ingestion, inhalation and dermal contact are the main pathways for metal exposures to dwelling populace. Especially, the major cause of cancer risk is due to exposure of Arsenic, Nickel and Cadmium (Alfaro et al., 2015). Besides, $\mathrm{Cr}(\mathrm{VI})$ pose high toxicity and carcinogenic risk to human through exposure by inhalation (US EPA, 2011). Furthermore, chronic ingestion of $\mathrm{Cd}$ and excessive

100 intake of $\mathrm{Pb}$ can cause negative health impacts like kidney dysfunction, bone fractures and hypertension etc.

101 Therefore, excessive metal exposure is hazardous to human health.

102 It is a vital issue to investigate human exposure to heavy metals in CHT soils to explore the adverse effects to the 103 dwellers and to protect human health. Generally, several steps should be followed to assess the chemical hazards 104 like identification, characterization, exposure assessment and risks characterization (Wild Thurst of Bangladesh, 105 2010). However, the prior task is the accurate determination of metal levels in the soils of interest for which 106 chemical hazards should be investigated.

107 Numerous studies of the three districts separately are available on the metal contamination in soils, water and 108 sediments, however, this study has focused on the assessment of the quality of soils combinedly in Rangamati, 109 Khagrachari and Bandarban of CHT area (Barua et al., 2019; Biswas et al., 2010; Osman, 2014; Wang et al., 110 2016). The study not only evaluated eight different metals such as Lead, Cadmium, Copper, Zinc, Iron, 111 Manganese, Nickel and Chromium but also many well-defined hazards characterization parameters/indices such 
112 as geo-accumulation index $\left(\mathrm{I}_{\mathrm{geo}}\right)$, contamination factor $(\mathrm{CF})$, pollution load index (PLI), enrichment factor (EF)

113 and potential ecological risk index (PERI) were used to assess environmental risk. In the same vein, this study

114 also assessed the non-carcinogenic and carcinogenic health risk for human beings from concerned metal elements.

115 Besides, multivariate statistical analysis is used to understand the behaviour of trace elements in the studied areas

116 by dividing a set of data objects into groups of similar characteristics. So, the present study is a comprehensive

117 one where pollution parameter in soil was analysed in various ways.

118 To ensure a safer eco-system and health of the dwelling populace, especially the less educated ethnic peoples who 119 depend on the natural resources of the CHT area for their livelihood, it is crucial to evaluate the quality of hilly

120 soils w.r.t. the metal levels of carcinogenic and non-carcinogenic category. In this regards, our study was aimed

121 to establish a benchmark of quality for $\mathrm{Pb}, \mathrm{Cd}, \mathrm{Cu}, \mathrm{Zn}, \mathrm{Fe}, \mathrm{Mn}, \mathrm{Ni}$, and $\mathrm{Cr}$ in the soil of CHT that gives a base for 122 monitoring metal levels in soils. [10].

123

124 2. Methodology

125 2.1. Description of the study area

126 The south-eastern part of Bangladesh is a wide-ranging hilly area, known as Chattogram Hill Tracts (CHT). It is 127 occupied by 13,294 sq km of the area [5]. Most of the area of CHT is humid tropical rainforests with a high 128 diversity of flora and fauna. It is located between $21^{\circ} 25^{\prime} \mathrm{N}$ to $23^{\circ} 25^{\prime} \mathrm{N}$ latitude and $91^{\circ} 54^{\prime} \mathrm{E}$ to $92^{\circ} 50^{\prime} \mathrm{E}$ 129 longitude [6], [15]. The present study area consists of three distinct geographical and cultural landscape districts 130 which are Rangamati $(\mathrm{Rm})\left(22^{\circ} 37^{\prime} 60 \mathrm{~N}-92^{\circ} 12^{\prime} \mathrm{OE}\right)$, Khagrachari $(\mathrm{Kc})\left(23^{\circ} 04.051 \mathrm{~N}-91^{\circ} 87.566 \mathrm{E}\right)$ and Bandarban 131 (Bb) $\left(22^{\circ} 11.121 \mathrm{~N}-92^{\circ} 23.416 \mathrm{E}\right)$ [13]. The CHT covers $43 \%$ forest area of Bangladesh (Bangladesh Forest 132 Department, 2016). More than 70\% area in both natural and plantation forests of Bangladesh covers by the CHT 133 areas [4].

\section{$135 \quad 2.2$ Sample collection}

136 A representative number of topsoil samples ( $\mathrm{n}=37$ ) (up to $20 \mathrm{~cm}$ deep from the top surface) were collected from 137 the studied area. The distance between two consecutive sampling locations was 200-250 m depending primarily 138 on local terrain and accessibility. The geographical coordinates (latitude and longitude) of the location of each 139 sampling point were recorded using a GPS of google map. The collected soils samples are mainly of yellowish140 brown to reddish-brown loams. The collected samples were brought to the laboratory of Atomic Energy Centre, 141 Chattogram for subsequent preparation and analyses.

\subsection{Sample Preparation}

144 The collected soil samples were cleaned by removing any foreign media. A large sieve was used to remove stones, 145 rocks, concrete, roots or other organic matter from the soil. The collected soil samples were sun-dried for one 146 week and then kept in acid-washed containers and placed in an oven at $50^{\circ} \mathrm{C}$ for 48 hours. Soil samples were then 147 fully crushed to the finest possible fraction using acid-washed pestle and mortar then clear 2 mm sieve. Later, 148 samples were kept in zip bag separately and stored in desiccators. 
$1515 \mathrm{~g}$ of each soil sample was picked by a high precision analytical balance and then transferred to an acid-washed

152 glass beaker. Then samples were weighted and added $15 \mathrm{~mL} \mathrm{HNO}_{3}(69 \%)$. Then it was placed in an electric

153 heater at $60^{\circ} \mathrm{C}$ for half an hour. The beaker covered with a watch glass. The electric hot plate was used for heating

154 as it regulates the temperature better and distributes the temperature evenly. After then the temperature range was

155 increased up gradually to $100^{\circ} \mathrm{C}$ until the concentration becomes half of the initial volume (Aga and Brhane,

156 2014).

157 After cool down the samples to room temperature, they were filtered $(0.8 \mu \mathrm{m})$ through a glass funnel containing

158 Whattman No.1 filter paper. Then the solutions were diluted with deionized water to a final volume of $50 \mathrm{~mL}$

159 (Lubomir Svoboda, 2016) and stored in 50ml plastic centrifuge test tube vial container.

160

1612.5 Analytical procedure

162 The acid digested triplicates samples were analyzed for the determination of heavy metals $(\mathrm{Pb}, \mathrm{Cd}, \mathrm{Cu}, \mathrm{Zn}, \mathrm{Fe}$,

$163 \mathrm{Mn}, \mathrm{Ni}$ and $\mathrm{Cr}$ ) by atomic absorption spectrophotometry (AAS). Results (in ppm) are expressed on a dry weight

164 basis of each element. A blank solution was also run under the same analytical conditions without the addition of

$165 \mathrm{~Pb}, \mathrm{Cd}, \mathrm{Cu}, \mathrm{Zn}, \mathrm{Fe}, \mathrm{Mn}, \mathrm{Ni}$ and $\mathrm{Cr}$.

166 For digesting composts, the nitric acid procedure was used into a traditional open-vessel digestion system for the

167 sake of recovering the analysis, saving money, efficiency and hazardousness (Material, 2017). The metal ions on

168 prepared sample solutions were characterized by Z-2000 polarized Zeeman atomic absorption spectrophotometer

169 to determine the amount of investigated metal ions.

170

\subsection{Standard Solutions}

172 Analytical grade reagents were used in this study. Purified de-ionized water was used for all sample preparation 173 and dilution purposes throughout our study. Standard solutions of the studied metals were made based on dilution 174 of certified standard solutions of corresponding metal ions (Khandaker et al., 2015). The standard solutions were 175 used in preparing subsequent calibration curves after serial dilutions. After finishing the analytical work, all the 176 glass apparatus were immersed into the dilute $\mathrm{HNO}_{3}$ for overnight and then washed with deionized water to 177 remove impurity repeatedly. Four standard solutions of different known concentrations were prepared and the 178 corresponding concentration in the unknown sample was deduced by estimation from the calibration curve. 179 Standard unit, $\mathrm{mg} / \mathrm{kg}$ was used to report the concentration of the measured samples (Stihi et al., 2011).

$$
\text { Concentration }(\mathrm{mg} / \mathrm{kg})=\frac{(\mathrm{mg} / \mathrm{kg} \text { in sample solution }) \times 50}{\text { sample weight in grams }}
$$

The concentration of $\mathrm{Fe}, \mathrm{Mn}$ and $\mathrm{Zn}$ metals in soil were calculated using the formula below (Perkin Elmer, 1996).

$$
\text { Concentration }(\mathrm{mg} / \mathrm{kg})=\frac{\mathbf{C M} \times \mathbf{D F} \times \mathbf{N V}}{\mathbf{S V}}
$$

183 Where: $\mathrm{CM}=$ Concentration of metal, $\mathrm{DF}=$ Dilution factor, $\mathrm{NV}=$ Nominal volume,

$184 \mathrm{SV}=$ Sample volume $(\mathrm{mL})$.

185

186

\subsection{Soil pollution quantification}


187 Several methods are available for assessing the degree of metal concentration in soil. Some common methods are

188 used to compare the identified concentrations with a background level or with a concentration posing serious

189 environmental risks. Five indices were used to evaluate the quality of the studied pollutants in the hilly soils.

190

$191 \quad 2.7 .1$ Geo-accumulation Index $\left(I_{g e o}\right)$

192 Geoaccumulation Index $\left(\mathrm{I}_{\text {geo }}\right)$ is used, as an indicator, for assessing the intensity of anthropogenic contaminant

193 level on surface soil and to evaluate the pollution in the terrestrial, aquatic and marine environment. The geo-

194 accumulation index is expressed as follows(Zinkute et al., 2017):

$$
\mathrm{I}_{\text {geo }}=\log _{2}\left(\frac{C_{n}}{1.5 B_{n}}\right)
$$

Where, Cn: the measured concentration of heavy metal (n) in the soil,

$\mathrm{Bn}$ : the geochemical background value in average shale of element $\mathrm{n}$,

1981.5 is the background matrix correction factor detecting very small anthropogenic influence (Muzerengi, 2017).

199 Here, the chemical composition of unaffected soil at a remote/nondisturbed site of the study area was chosen as 200 the background value.

201 The $\mathrm{I}_{\text {geo }}$ is identified with a qualitative range of pollution intensity for seven groups of pollution from unpolluted $202 \quad\left(I_{\text {geo }} \leq 0\right)$ to extremely polluted $\left(I_{\text {geo }}>6\right)$ and stated for the quality of soils based on $I_{\text {geo }}$ values. Geo-accumulation 203 index has seven classifications (Muzerengi, 2017) depending on its value: < 0 (unpolluted), $0-1$ (no or minimally 204 polluted), $1-2$ (moderately polluted), $2-3$ (moderately polluted to polluted), $3-4$ (polluted to strongly polluted), $2054-5$ (strongly polluted), 5-6 (strongly polluted to very strongly polluted), > 6 (very strongly polluted).

\subsubsection{Contamination factor $(\mathrm{CF})$}

208 Contamination factor (CF) is known as a single pollution index (PI). It exposes the anthropogenic input in elemental pollution (Pandey et al., 2016). It measures the overall contamination level of a sampling site by heavy metals. It can be calculated by taking the ratio of measured concentration for each metal to the background values

211 (Muzerengi, 2017; Sana 'a Odat, 2013):

$$
\mathrm{CF}=\frac{C_{\text {metal }}}{C_{\text {background value }}}
$$

213 Where, $\mathrm{C}_{\text {metal }}$ : the metal concentration in polluted soil,

$214 \quad \mathrm{C}_{\text {Background value }}$ : the background value of that metal.

215 The CF being classified into four grades (Pandey et al., 2016) for monitoring the pollution of one single metal

216 over a while: $<1$ (low degree), 1 to $<3$ (moderate degree), 3 to $<6$ (considerable degree), $\geq 6$ (very high degree).

\section{$218 \quad$ 2.7.3 Pollution load index (PLI)}

219 The pollution load index (PLI) is a simple statistical technique. It provides major information about metal pollution 220 in the soil samples. The PLI is calculated from the geometric mean of the CFs of measured elements 221 (Abdulqaderismaeel and Kusag, 2015; Zinkutè et al., 2017). 
Where, CF : the contamination factor,

$\mathrm{n}:$ the number of studied metals.

By using PLI, the degree of pollution is classified as follows: $>1$ (pollution i.e. deterioration of soil quality), $<1$ (indicates no pollution), 1 (baseline pollution) (Abdulqaderismaeel and Kusag, 2015; Zinkutẻ et al., 2017).

\subsubsection{Enrichment factor $(E F)$}

229 The enrichment factor (EF) indicates the concentration of any metal against a reference value. A geochemically 230 distinguishing element and consisting of a high concentration in the environment can be used as a reference 231 element. In this study, iron $(\mathrm{Fe})$ is employed as the reference element which is used for normalization (Afzal et 232 al., 2014; Pandey et al., 2016).

$$
\mathrm{EF}=\frac{(\text { Element concentration }) /(\mathrm{Fe} \text { concentration })_{\text {Sample }}}{(\text { Element concentration }) /(\mathrm{Fe} \text { concentration })_{\text {Shale }}}
$$

234 To determine both natural and anthropogenic metal source and the degree of anthropogenic influence, EF is widely used. On the other hand, the value of EF > 2 indicates an anthropogenic source of metal enrichment, and based on this value, $\mathrm{EF}$ is further classified as $2-5$ (moderate enrichment), $5-20$ (significant enrichment), > 40 (extremely high enrichment).

\subsubsection{Potential ecological risk index (PERI)}

240 The potential ecological risk caused by heavy metals in the soil can be evaluated by using the potential ecological 241 risk index (PERI, or RI) (Gbadamosi et al., 2018). This method evaluates four parameters such as concentration, 242 pollutant types, level of toxicity and sensitivity of the water body in the soil (Gbadamosi et al., 2018). PERI is 243 calculated as:

$$
\text { PERI }=\sum_{\mathrm{i}=0}^{\mathrm{n}} \mathrm{E}_{\mathrm{r}}^{\mathrm{i}}=\sum_{\mathrm{i}=0}^{\mathrm{n}} \mathrm{T}_{\mathrm{r}}^{\mathrm{i}} \times \mathrm{C}_{\mathrm{f}}^{\mathrm{i}}
$$

where $E_{r}^{i}=$ the potential ecological risk factor of each heavy metals. $C_{f}^{i}=$ the contamination factor of heavy metal, $\mathrm{i}$.

249 The $E_{r}^{i}$ is described in five categories: $<40$ (low), 40 to $<80$ (moderate), 80 to $<160$ (considerable), 160 to $<200$

250 (high), < 320 (very high) (Fiori et al., 2013). PERI represents the total value of all measured heavy metal's 251 potential ecological risk factors $\left(E_{r}^{i}\right)$ in four categories: $<150$ (low), 150 to $<300$ (moderate), 300 to $<600$ (considerable), and > 600 (very high) (Gbadamosi et al., 2018).

\subsection{Multivariate statistical analysis (MSA)}

255 With the use of MSA, one can easily determine the underlying structures of large datasets and also identify the 256 latent factors that may help to understand the sources of metals pollution/contamination (Hou et al., 2017). It 257 includes mainly principal component analysis (PCA) and cluster analysis (CA), was performed with IBM SPSS 258 (Statistical Programme for Social Sciences) V26.0 software for PCA tools. 
261 The PCA is a data dimension reduction technique. It aims to interpret most of the variance in the data with a small

262 number of independent variables (principal components) (Hou et al., 2017). It also used to identify a set of factors present in the data. Factors were rotated using the varimax method which simplified the understanding of output results by decreasing the number of variables that loaded to high loads on each component. The Kaiser-MeyerOlkin Measure of Sampling Adequacy (KMO) and Bartlett's Test of Sphericity normalization were used where the factors are independent of each other.

\subsubsection{Hierarchical Cluster analysis $(H C A)$}

269 HCA was used to identify analogous behaviour among the different parameters. It is the foremost statistical method to identify homogeneous groups of cases based on the measured characteristics (Zolfaghari et al., 2019). The squared Euclidean distance is used to address how to distance the variables, it is essential to select the clustering algorithm to lead the distances of the points that are determined to specify cluster membership. Ward's method is the most frequently used algorithms to analyse the variance approach in assessing the inter-clusters distances.

\subsection{Potential Health Risk Assessment}

\subsubsection{Non-carcinogenic risk}

The US-EPA developed models to calculate the detrimental impacts of heavy metals on human health considering carcinogenic and non-carcinogenic risk (Gbadamosi et al., 2018; Jia et al., 2018; Wahab et al., 2020). Potential risk assessment posed by heavy metals from the soils through multiple routes of exposure is divided into four steps: identification of hazards, dose-response assessment, assessment of exposure, and characterization of risk (Gbadamosi et al., 2018; Gržetić and Ahmed Ghariani, 2008).

283 In the present case, $\mathrm{Pb}, \mathrm{Cd}, \mathrm{Cu}, \mathrm{Zn}, \mathrm{Fe}, \mathrm{Mn}, \mathrm{Ni}$ and $\mathrm{Cr}$ were identified as the potentially hazardous agents in the soil of CHT. By using the average daily dose (ADD), three main pathways for heavy metals exposure to human were considered here: direct ingestion of soil particles $\left(\mathrm{ADD}_{\mathrm{ing}}\right)$, inhalation of suspended soil particles from the air through nose and mouth $\left(\mathrm{ADD}_{\mathrm{inh}}\right)$, and absorption of heavy metals from skin adhered soil, called as dermal contact $\left(\mathrm{ADD}_{\text {dermal }}\right)$.

288 The ADD ( $\left.\mathrm{mg} \mathrm{kg}^{-1} \mathrm{day}^{-1}\right)$ can be estimated by using the equations (2.8)-(2.10) (Gbadamosi et al., 2018; Jia et al., 289 2018; Wahab et al., 2020):

$$
\mathrm{ADD}_{\text {ing }}=\frac{\mathrm{C}_{\text {soil }} \times \mathrm{R}_{\text {ing }} \times \mathrm{EF} \times \mathrm{ED}}{\mathrm{BW} \times \mathrm{AT}_{\text {noncarc }}} \times 10^{-6}
$$

$$
\mathrm{ADD}_{\text {inh }}=\frac{\mathrm{C}_{\text {soil }} \times \mathrm{R}_{\text {inh }} \times \mathrm{EF} \times \mathrm{ED}}{\mathrm{PEF} \times \mathrm{BW} \times \mathrm{AT}_{\text {noncarc }}}
$$

$$
\mathrm{ADD}_{\text {derm }}=\frac{\mathrm{C}_{\text {soil }} \times \mathrm{SA} \times \mathrm{SL} \times \mathrm{ABS} \times \mathrm{EF} \times \mathrm{ED}}{\mathrm{BW} \times \mathrm{AT}_{\text {noncarc }}} \times 10^{-6}
$$

293 The values of all parameters in Eqs. (2.8-2.10) are given in Table 1. By using the obtained values of ADDs, the 294 non-carcinogenic risk of heavy metals in CHT soil was evaluated via a parameter called hazard quotient (HQ) for a single substance, or ( $\Sigma \mathrm{HQ})$ for multiple substances: 
297 Where $\mathrm{R}_{\mathrm{f}} \mathrm{D}$ stands for reference dose, values are available in Table 3. The cumulative non-carcinogenic risk for 298 multiple substances can be expressed as a hazard index (HI) [14] [34]:

$$
\mathrm{HI}=\sum H Q_{\text {ing }+ \text { inh }+ \text { derm }}
$$

300 It is considered as 'no significant risk' for $\mathrm{HI} \leq 1$, and indicates the probability of occurrences of non-carcinogenic effects for $\mathrm{HI}>1$, and it increases with an increasing value of HI (Gbadamosi et al., 2018).

\subsubsection{Carcinogenic risk (CR)}

The individual lifetime cancer risk can be calculated by CR. It can be obtained by multiplying lifetime average daily dose (LADD) (mg/kg-day) associated with ingestion, inhalation and dermal contact exposure for children and adult with the cancer slope factor (SF) (mg/kg-day), as follows:

$$
\mathrm{CR}=\mathrm{LADD} \times \mathrm{SF}
$$

307 The following equations are applicable to determine the LADDs (Johnbull et al., 2019; US EPA, 2011; Wahab et al., 2020):

$$
\begin{aligned}
& \mathrm{LADD}_{\text {ing }}=\frac{\mathrm{C}_{\text {soil }} \times \mathrm{R}_{\text {ing }} \times \mathrm{EF} \times \mathrm{ED}}{\mathrm{BW}_{\mathrm{NAT}} \mathrm{A}_{\text {carc }}} \times 10^{-6} \\
& \mathrm{LADD}_{\text {inh }}=\frac{\mathrm{C}_{\text {soil }} \times \mathrm{R}_{\text {inh }} \times \mathrm{EF} \times \mathrm{ED}}{\text { PEF } \times \mathrm{BW} \times \mathrm{AT}_{\text {carc }}}
\end{aligned}
$$

312

$$
\mathrm{LADD}_{\text {derm }}=\frac{\mathrm{C}_{\text {soil }} \times \mathrm{SA} \times \mathrm{SL} \times \mathrm{ABS} \times \mathrm{EF} \times \mathrm{ED}}{\mathrm{BW} \times \mathrm{AT}_{\text {carc }}} \times 10^{-6}
$$
$313 \mathrm{~Pb}$, inhalation of $\mathrm{Pb}, \mathrm{Cd}, \mathrm{Ni}$ and $\mathrm{Cr}$, and dermal of $\mathrm{Pb}$. For dermal exposure, cancer slope factor ( $\mathrm{SF}$ ) is not 314 available, but it can be found by multiplying the oral cancer slope by the gastro-intestinal absorption factor 315 (Johnbull et al., 2019). All health risks are cumulative [14], [34], therefore the total cancer risk (lifetime 316 carcinogenic risk) was calculated by summing the individual cancer risk as follows (Jia et al., 2018).

$$
\mathrm{TCR}=\sum \mathrm{CR}=\mathrm{CR}_{\text {ing }}+\mathrm{CR}_{\text {inh }}+\mathrm{CR}_{\mathrm{derm}}
$$

318 The carcinogenic risks to human health from the soil can be considered negligible $\left(\mathrm{CR}<10^{-6}\right)$, non-negligible $319\left(\mathrm{CR}=10^{-6}\right.$ to $\left.10^{-4}\right)$, and a high risk for the development of cancer in humans $\left(\mathrm{CR}>10^{-4}\right)$ (Weissmannová et al., 320 2019).

321 Table 1: Variables and parameter of exposure applied in health risk assessment calculation (US EPA, 2011).

\begin{tabular}{|l|l|l|l|l|}
\hline Variable & Definition & \multicolumn{2}{l|}{ Value used } & Reference \\
\cline { 3 - 5 } & & Children & Adult & \\
\hline $\mathrm{C}_{\text {Soil }}(\mathrm{mg} / \mathrm{kg})$ & Concentration of metal in soil & & & \\
\hline $\mathrm{R}_{\text {ing }}(\mathrm{mg} / \mathrm{day})$ & Ingestion rate & 200 & 100 & $\begin{array}{c}\text { (Wahab et } \\
\text { al., 2020) }\end{array}$ \\
\hline
\end{tabular}




\begin{tabular}{|c|c|c|c|c|}
\hline $\mathrm{AT}_{\text {noncarc }}$ & $\begin{array}{l}\text { Averaging time for non- } \\
\text { carcinogens }\end{array}$ & $\begin{array}{l}365 \text { days/year/ } \\
\times \mathrm{ED}\end{array}$ & $\begin{array}{l}365 \text { days/year } \times \\
\text { ED }\end{array}$ & $\begin{array}{l}\text { (Wahab et } \\
\text { al., 2020) }\end{array}$ \\
\hline BW & Average body weight & $15 \mathrm{~kg}$ & $70 \mathrm{~kg}$ & $\begin{array}{l}\text { (US EPA, } \\
2011 ; \\
\text { Wahab et } \\
\text { al., 2020) }\end{array}$ \\
\hline $\mathrm{EF}$ & Exposure frequency & 350 days/year & 350 days/year & $\begin{array}{l}\text { (Wahab et } \\
\text { al., 2020) }\end{array}$ \\
\hline $\mathrm{R}_{\text {inh }}$ & Inhalation rate & $7.6 \mathrm{~m}^{3} /$ day & $20 \mathrm{~m}^{3} /$ day & $\begin{array}{l}\text { (Wahab et } \\
\text { al., 2020) }\end{array}$ \\
\hline PEF & Particle emission factor & $1.36 \times 10^{9} \mathrm{~m}^{3} / \mathrm{kg}$ & $1.36 \times 10^{9} \mathrm{~m}^{3} / \mathrm{kg}$ & $\begin{array}{l}\text { (Gbadamosi } \\
\text { et al., 2018; } \\
\text { Wahab et } \\
\text { al., 2020) }\end{array}$ \\
\hline $\mathrm{AT}_{\text {carc }}$ & Averaging time for carcinogens & 25550 days & 25550 days & $\begin{array}{l}\text { (US EPA, } \\
2011 ; \\
\text { Wahab et } \\
\text { al., 2020) }\end{array}$ \\
\hline SA & $\begin{array}{l}\text { Surface area of the skin that } \\
\text { contacts the soil }\end{array}$ & $2800 \mathrm{~cm}^{2}$ & $5700 \mathrm{~cm}^{2}$ & $\begin{array}{l}\text { (US EPA, } \\
2011 ; \\
\text { Wahab et } \\
\text { al., 2020) }\end{array}$ \\
\hline SL & $\begin{array}{l}\text { Skin adherence factor for the } \\
\text { dust }\end{array}$ & $0.2 \mathrm{mg} / \mathrm{cm}^{2}$ & $0.07 \mathrm{mg} / \mathrm{cm}^{2}$ & $\begin{array}{l}\text { (Wahab et } \\
\text { al., 2020) }\end{array}$ \\
\hline ED & Exposure duration & 6 years & 24 years & $\begin{array}{l}\text { (US EPA, } \\
2011 ; \\
\text { Wahab et } \\
\text { al., 2020) }\end{array}$ \\
\hline ABS & Dermal absorption fraction & 0.001 & 0.001 & $\begin{array}{l}\text { (Wahab et } \\
\text { al., 2020) }\end{array}$ \\
\hline
\end{tabular}

\section{3. Results and Discussion}

324 3.1. Level of heavy metals in soil samples

325 Accumulation of an excessive amount of heavy metals in the organic layer and topsoil over a long period 326 eventually contaminate the soil organisms, hence affect the sustainability and productivity of terrestrial 327 ecosystems (Chrzan et al., 2013).

328 In general, a $\mathrm{pH}$ value of $>4.0$ helps in the accumulation of $\mathrm{Pb}$ in the organic and upper mineral layer of soil 329 (Rademacher, 2001). The $\mathrm{Pb}$ concentrations $(\mathrm{mg} / \mathrm{kg})$ in the studied sample were ranged from $3.8 \pm 0.004$ to $33032.7 \pm 0.071$ which was lower than the world average ( $2-300 \mathrm{mg} / \mathrm{kg}$ ) (Alfaro et al., 2015). The concentration of $331 \mathrm{Cd}(\mathrm{mg} / \mathrm{kg})$ was found between $0.03 \mathrm{mg} / \mathrm{kg}$ to $0.25 \mathrm{mg} / \mathrm{kg}$ which was lower value compared with the world 332 average (0.01-2.0 mg/kg) (Alfaro et al., 2015). An unusual of the highest level of $\mathrm{Cu}$ was found $172.5 \pm 0.003$ $333 \mathrm{mg} / \mathrm{kg}$ in Rm-3 site and the smallest level of $3.9 \pm 0.1 \mathrm{mg} / \mathrm{kg}$ was found in Rm-6. The world average for $\mathrm{Cu}$ in the 334 soil is $2-250 \mathrm{mg} / \mathrm{kg}$ (Alfaro et al., 2015).

335 The highest and significant different value was available at $\mathrm{Rm}-2(202.60 \mathrm{mg} / \mathrm{kg})$. The minimum value of $\mathrm{Zn}$ 336 found in Kc-6 area was $13.6 \pm 0.04 \mathrm{mg} / \mathrm{kg}$. The world average of zinc in soils is $1-900 \mathrm{mg} / \mathrm{kg}$ (Alfaro et al., 2015). 337 Fe was determined in a range of $14004.6 \pm 82.63 \mathrm{mg} / \mathrm{kg}-108354.6 \pm 162.53 \mathrm{mg} / \mathrm{kg}$ in the studied samples. The 
338 literature revealed that iron concentrations vary with the depth of the soil (20,000 to 550,000 $\mathrm{mg} \mathrm{kg}^{-1}$ ) (Anumalla

339 Mahender, B. P. Mallikarjuna Swamy, 2019). Manganese content in this study was in the range of $1289.9 \pm 12.14$

$340 \mathrm{mg} / \mathrm{kg}$ (sample Rm-7) - 73.4 $\pm 1.05 \mathrm{mg} / \mathrm{kg}$ (sample Kc-3) in high hill soils. The world average of manganese

341 content is $540 \mathrm{mg} / \mathrm{kg}$ (Pandey et al., 2016). A significant difference and the highest concentrations of Ni

$342(38.12 \pm 0.206 \mathrm{mg} / \mathrm{kg})$ was found at $\mathrm{Bb}-8$ area whereas the minimum value of $\mathrm{Ni}$ was $1.91 \pm 0.003 \mathrm{mg} / \mathrm{kg}$. The world

343 average range of $\mathrm{Ni}$ is $2-750 \mathrm{mg} / \mathrm{kg}$ ) (Alfaro et al., 2015). The value of $\mathrm{Cr}$ in the soil samples was found to be in

344 the range of $4.2 \pm 0.004$ and $70.5 \pm 0.317 \mathrm{mg} / \mathrm{kg}$. The world average of $\mathrm{Cr}$ is $48 \mathrm{mg} / \mathrm{kg}$ [11].

345 Overall, the soil in samples collected from three districts was less contaminant by all studied metals and less

346 harmful to the environment (Rademacher, 2001).

\subsection{Assessment of soil contamination}

349 The degree of heavy metals contamination in the CHT soils was assessed by some indices, and they are discussed 350 here.

\section{$351 \quad 3.2 .1$ Geo-accumulation index $\left(I_{g e o}\right)$}

352 The value of $I_{\text {geo }}$ indicates the presence and also the intensity of anthropogenic contaminants deposition on the 353 soil. Overall metal contamination level in the soils shows in Table 3 was calculated by the $\mathrm{I}_{\text {geo }}$. The mean $\mathrm{I}_{\mathrm{geo}}$ 354 values for all metals were found in the range of -5.74 to 1.35 , which indicates a non-contamination of some soils 355 and some are unpolluted to moderately polluted. $\mathrm{Rm}-3$ is moderately polluted because of copper concentration 356 (Muzerengi, 2017).

\subsubsection{Contamination factor $(C F)$}

358 Table 2 shows the calculated CFs in the range of $0.97-3.83$, which indicates that some metals exceeded the background level. The $\mathrm{CF}$ showed considerable contamination by $\mathrm{Zn}$ and $\mathrm{Fe}$, moderately contamination by $\mathrm{Pb}$ and $\mathrm{Mn}$, and practically no contamination by $\mathrm{Cd}, \mathrm{Ni}$ and $\mathrm{Cr}(\mathrm{CF}<1.5)$. Based on the mean values of $\mathrm{CF}$, soils were enriched with metals in the following order: $\mathrm{Fe}>\mathrm{Zn}>\mathrm{Cu}>\mathrm{Mn}>\mathrm{Pb}>\mathrm{Cd}>\mathrm{Ni}>\mathrm{Cr}$. This indicated that the soils at $\mathrm{Rm}-$ 3 and most of the sites of Bandarban have been largely polluted by $\mathrm{Fe}, \mathrm{Zn}$ and $\mathrm{Cu}$. Overall, all calculated metals showed a moderate degree of contamination $(1 \leq \mathrm{CF}<3)$ except $\mathrm{CF}$ of $\mathrm{Cu}(3.83)$. The calculation revealed that

364 Fe has the highest pollution and the $\mathrm{CF}$ value of $\mathrm{Cu}$ in Rangamati district (specially $\mathrm{Rm}-3$ ) was high (Širić et al., 365 2016).

\subsubsection{Pollution load index (PLI)}

367 The spatial distribution of metal contaminants in the study area was demonstrated by the pollution load index and 368 is shown in Table 2. The PLI values were ranged from 0.27 to 0.62 in Rangamati district, from 0.15 to 0.42 in 369 Khargachari district and from 0.32 to 0.75 in Bandarban district. Calculated values (PLI < 1) confirmed that the 370 soil of the studied area was less contaminated by metals.

372 The result of EFs (shown in Table 2) indicated a homogeneous distribution of the studied metals throughout the 373 sample areas. It was found that the soil samples of most of the area were depletion to mineral enrichment with the 
metals. The EF values for $\mathrm{Cu}$ and $\mathrm{Zn}$ were found not exceeding the level of moderate enrichment $(\mathrm{EF}<5)$. The maximum $\mathrm{EF}$ value of $\mathrm{Cu}$ was 4.99 , consequently signifying soil enrichment by this metal. According to the enrichment factor, high concentration of $\mathrm{Cu}$ in the soil of Rm-3 area is harmful to plants and can be transmitted to human beings through the food chain. So, $\mathrm{Rm}-3$ was extremely enriched by $\mathrm{Cu}$ with significantly high enriched by $\mathrm{Pb}$ (1.22), $\mathrm{Cd}$ (1.09) and $\mathrm{Zn}$ (2.73). Besides, the soil of Rm-3, Kc-14 was found to be moderately enriched by $\mathrm{Pb}, \mathrm{Cd}, \mathrm{Cu}$ and $\mathrm{Zn}$ (Ahammad and Stacey, 2016; Miah et al., 2010).

Table 2: Descriptive statistics of Geo-accumulation Index, contamination factor, pollution load and enrichment factor index for the CHT area.

\begin{tabular}{|c|c|c|c|c|c|c|c|c|c|}
\hline Descriptive statistics & $\mathrm{Pb}$ & $\mathrm{Cd}$ & $\mathrm{Cu}$ & $\mathrm{Zn}$ & $\mathrm{Fe}$ & Mn & $\mathrm{Ni}$ & $\mathrm{Cr}$ & \\
\hline \multicolumn{10}{|l|}{$\begin{array}{l}\text { Geo-accumulation Index } \\
\left(\mathrm{I}_{\mathrm{geo}}\right)\end{array}$} \\
\hline Max. & 0.12 & -0.85 & 1.35 & 0.51 & 0.61 & 0.02 & -1.42 & -0.94 & \\
\hline Min. & -2.98 & -4.49 & -4.11 & -3.39 & -2.34 & -4.12 & -5.74 & -5.08 & \\
\hline Mean & -1.78 & -1.87 & -1.76 & -1.62 & -0.57 & -2.12 & -3.39 & -2.95 & \\
\hline \multicolumn{10}{|l|}{$\begin{array}{l}\text { Contamination factor } \\
\text { (CF) }\end{array}$} \\
\hline Max. & 1.64 & 0.83 & 3.83 & 2.13 & 2.30 & 1.52 & 0.56 & 0.78 & \\
\hline Min. & 0.19 & 0.07 & 0.09 & 0.14 & 0.30 & 0.09 & 0.03 & 0.04 & \\
\hline Mean & 0.52 & 0.47 & 0.58 & 0.59 & 1.11 & 0.43 & 0.17 & 0.27 & \\
\hline \multicolumn{10}{|l|}{ Pollution load index (PLI) } \\
\hline Max. & $\cdots$ & $\ldots$ & $\cdots$ & $\cdots$ & $\ldots$ & $\cdots$ & $\ldots$ & $\cdots$ & 0.75 \\
\hline Min. & $\ldots$ & $\ldots$ & $\ldots$ & $\ldots$ & $\ldots$ & $\ldots$ & $\ldots$ & $\ldots$ & 0.15 \\
\hline Mean & $\ldots$ & $\ldots$ & $\ldots$ & $\ldots$ & $\ldots$ & $\ldots$ & $\ldots$ & $\ldots$ & 0.40 \\
\hline \multicolumn{10}{|l|}{ Enrichment factor (EF) } \\
\hline Max. & 1.23 & 1.12 & 4.99 & 2.73 & 1.00 & 1.76 & 0.49 & 1.61 & \\
\hline Min. & 0.25 & 0.04 & 0.10 & 0.15 & 1.00 & 0.10 & 0.06 & 0.05 & \\
\hline Mean & 0.49 & 0.50 & 0.63 & 0.62 & 1.00 & 0.39 & 0.16 & 0.29 & \\
\hline
\end{tabular}

382

According to the four pollution indices, it is observed that soil samples of Rangamati, Khagrachari and Bandarban occupied background concentrations for the studied elements, and no or unchanged by anthropogenic influences in true sense. However, some calculated values of pollution parameter for the different area were found relatively higher than others due to the influence of shifting agriculture, agricultural runoff and other anthropogenic inputs. Regular Joom (shifting) cultivation in CHT areas is also considered as one of the main reasons for forest degradation (Ahammad and Stacey, 2016; Miah et al., 2010).

\subsubsection{Potential ecological risk index (PERI)}

Figure 1 graphically shows the calculated potential ecological risk index of our study. Samples from Bandarban area was found to pose the highest ecological risk $(300 \leq \mathrm{RI}<600)$, while in Rangamati and Khagrachari area posed a moderate risk $(150 \leq \mathrm{PERI}<300)$. Based on the PERI value, $\mathrm{Cd}$ of the $\mathrm{Rm}, \mathrm{Kc}$ and $\mathrm{Bb}$ area were found to have a high potential risk $\left(E_{r}^{i}\right)$ i.e. 160,181 and 185 respectively in the soil. The PERI of our data indicated that the potentiality of pollution of the studied heavy metals decreased by the sequence of 


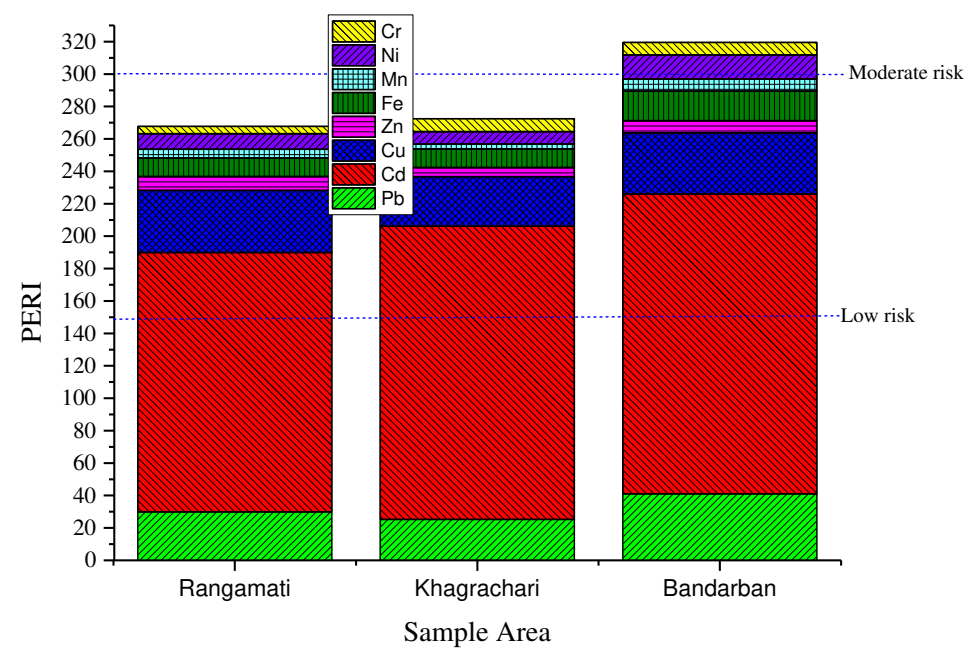

Fig1 Potential ecological risk indices (PERI) in the soil of CHT.

\subsection{Multivariate statistical analysis}

\subsubsection{Principal component analysis (PCA)}

In figure 2, the PCA with consistent data was used to interpret effectively the metal values determined in soil samples. Based on the eigenvalues greater than 1, three major components were identified, and it explains $70.850 \%$ of the system variance. As shown in figure-2, the variance of first principal component (PC-1) was $34.14 \%$ and eigenvalue was 2.731, showed strong positive loading in Fe (0.924), Ni (0.808), Mn (0.815) and moderate positive loading in $\mathrm{Pb}$ (0.620). Due to the highly positive loading of $\mathrm{Fe}$ and $\mathrm{Mn}, \mathrm{PC}-1$ could be clarified as natural sources (lithogenic activities)(Baltas et al., 2020). Ni contamination of soils resulted from the anthropogenic activities of plating works (Pandey et al., 2016).

The variance and eigenvalue of PC-2 were $21.151 \%$ and 1.692 that showed strong positive loading in $\mathrm{Cu}(0.920)$ and $\mathrm{Zn}(0.738)$ and moderate positive loading in $\mathrm{Pb}(0.528)$. PC-2 was suggesting that $\mathrm{Cu}$ and $\mathrm{Zn}$ from the lithogenic origin are affirmed to show close geo-chemical dependence as the iron family (Huang et al., 2020). Animal manure in the CHT forest soils is suggested to cause a significant increase in Zn levels (Baltas et al., 2020). Moreover, Lead was distributed between the two-component (PC-1 and PC-2) which is strongly bound by the organic matter of the surface soil layer. $\mathrm{Pb}$ isotopes are significant tools to control the respective contribution of lithogenic and anthropogenic sources in soils (Hernandez et al., 2003).

The variance and eigenvalue of PC-3 were $15.568 \%$ and 1.245 . The high loading factors detected for Cd (0.754) and $\mathrm{Cr}$ (0.744) in the PC-3 component. The anthropic inputs $\mathrm{Cr}$ showed a mixture source of both lithogenic and human origin in our study area (Baltas et al., 2020). The utmost toxic element, Cd which has high ecological risks are the source of pollutants. Extensive use of fertilizers (phosphate) is responsible for the variation of Cd (Zhang, 2016).

Overall, it is suggested that $\mathrm{Pb}, \mathrm{Cd}, \mathrm{Cr}$ and $\mathrm{Ni}$ are extremely affected by anthropogenic sources such as rubber factory, reverse cultivation, local combustions and applications of manure and agrochemicals in the study area 
424 a statistically significant difference between the soil samples in the investigated area.

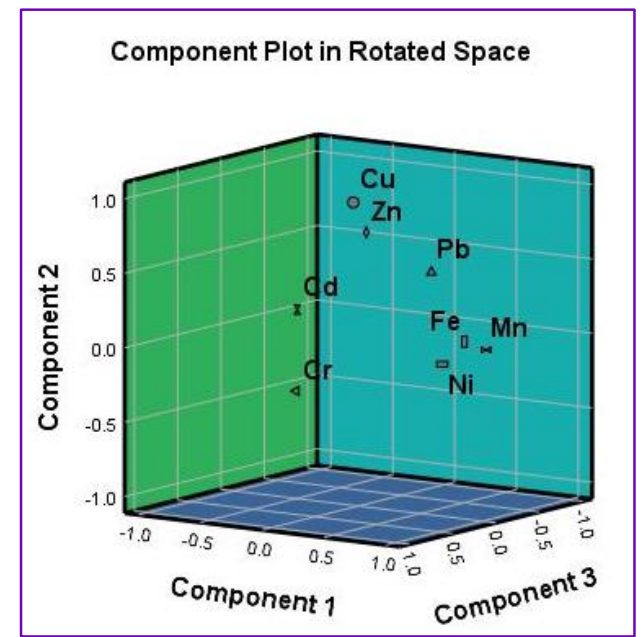

Fig2. PCA loading plot of studied heavy metals in rotated space.

\subsubsection{Cluster analysis}

The dendrogram (See in Fig. 3) connected to the analyzed metals has shown four main classes. The first class has been represented by $\mathrm{Mn}-\mathrm{Ni}, \mathrm{Pb}$ and $\mathrm{Fe}$, indicating a mixture of natural, lithogenic and anthropogenic sources in the studied area. Whereas lead is strongly bound by the organic matter of the surface forest soil layer (Chrzan et al., 2013) as well as nickel depends on the mineralogical structure of the soil. Nickel and lead are strongly influenced by iron oxide and hydroxides in the studies of soil samples (Chrzan et al., 2013; Kobierski and Dabkowska-Naskret, 2012).

The second class has been defined by $\mathrm{Cu}$ and $\mathrm{Zn}$, indicating the anthropogenic sources. The third and fourth classes have been defined by $\mathrm{Cd}$ and $\mathrm{Cr}$ which were completely isolated and discriminated the anthropogenic sources (Gbadamosi et al., 2018). $\mathrm{Cu}$ and $\mathrm{Zn}$ developed a sub-cluster that illustrated the major similarity with the cluster -1, also pointing to a similar source of pollution of the soil.

The results of the HCA analysis illustrated the same pollution sources as the origin of grouped metals. The weathering of parent materials may contribute to the high concentration of $\mathrm{Mn}$ and $\mathrm{Fe}$. The concentration of $\mathrm{Fe}$ and $\mathrm{Mn}$ indirectly indicates the presence of Fe or Mn oxides in surface soils that influenced heavy metals behaviour in soils. (Helena Doležalová Weissmannová, Silvie Miho`cová, 2019). Present results of HCA and PCA are supportive of the heavy metal contents with soil physicochemical characteristics. The difference between lithogenic and anthropogenic origin might be special effectiveness in case of risk assessments, deciding on remediation or apply restrictions to use the contaminated soil, information on the differences between lithogenic and anthropogenic origin is required. 


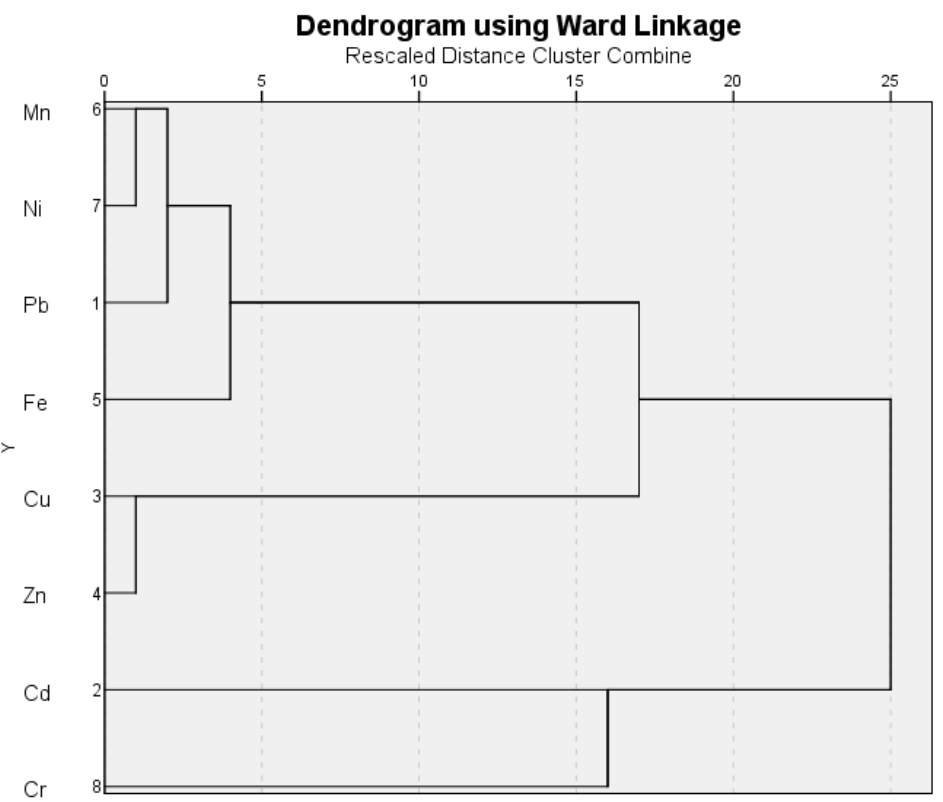

Fig3 Dendrogram showing hierarchical cluster analysis of analyzed metals of the studied area.

\subsection{Health Risk Assessment}

451 Exposure to metals might be responsible for detrimental health effects. The routes of exposure to heavy metals in soil samples of Rangamati, Khagracha and Bandarban include ingestion, inhalation and dermal contact. The calculated values of ADD ( $\left.\mathrm{mg} \mathrm{kg}^{-1} \mathrm{day}^{-1}\right)$ of three exposure pathways; ingestion, inhalation, and dermal contact were followed the Exposure Factors Handbook (Table 1) (US EPA, 2011).

\subsubsection{Noncarcinogenic risk}

456 The Reference dose of different metals mentioned in Table 3 was followed by previous literature (Afzal et al., 2014; Jia et al., 2018). In Table 3, the values of hazard quotients (HQ) via the three pathways in soils among the

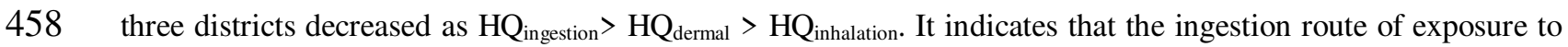
these heavy metals was the main human exposure pathways. Moreover, for children HQ (via all routes of exposures to studied metals) shows higher than adults which is similar to other studies around the world (Chonokhuu et al., 2019; Gbadamosi et al., 2018; Rastegari Mehr et al., 2017). The contribution of different metals to the non-carcinogenic risk (HQ) show the decreasing order of $\mathrm{Fe}>\mathrm{Mn}>\mathrm{Cr}>\mathrm{Pb}>\mathrm{Cu}>\mathrm{Ni}>\mathrm{Zn}>\mathrm{Cd}$ for both adults and children. However, there was no health risk to the CHT environment of individual metal present in the soil (Kacholi and Sahu, 2018).

Yet, the $\mathrm{HI}$ values were lower than the safe level $(\mathrm{HI} \leq 1)$ except Fe element which implies that there was no unusual non-carcinogenic risk due to these heavy metals for children and adults in the soil samples. $\mathrm{HI}>1$ for $\mathrm{Fe}$ in the three pathway for both adults and children indicates a potential risk to human health. However, iron does not show direct chemical toxicity according to an ecological risk perspective, but the effect of iron was referred as the geochemistry of other potentially toxic metals and the potential physical hazard of depositing flocculent Since the population will be exposed to all heavy metals instead of a single one, the use of integrated $\mathrm{HI}$ values $(\Sigma \mathrm{HI})$ is more practical to identify the real effect (Wahab et al., 2020). $\Sigma \mathrm{HI}$ exceeded 1 due to the high concentration level of Fe. So, based on $\Sigma \mathrm{HI}$ value in the studied area, children experience a higher risk of 
473 noncancer effects than adults. Since children directly involve themselves in hand-to-mouth activities (USEPA,

474 2011) (US EPA, 2011). Thus, there is a great possibility of incurring noncancerous effects and chronic diseases

475 such as loss of appetite, nausea, and headache to the populations of CHT (Fonseca-Nunes et al., 2014; Wahab et

476 al., 2020).

477 Table 3. The non-carcinogenic risk of HQs and HIs of the metal elements in the soil in children to adult.

\begin{tabular}{|c|c|c|c|c|c|c|c|c|c|}
\hline Metal & & $\mathrm{Pb}$ & $\mathrm{Cd}$ & $\mathrm{Cu}$ & $\mathrm{Zn}$ & $\mathrm{Fe}$ & $\mathrm{Mn}$ & $\mathrm{Ni}$ & $\mathrm{Cr}$ \\
\hline \multirow{3}{*}{$\begin{array}{l}\mathrm{R}_{\mathrm{f}} \mathrm{D} \\
\left(\mathrm{mg} \mathrm{kg}{ }^{-1} \mathrm{day}^{-1}\right)\end{array}$} & Ingestion & $3.50 \mathrm{E}-03$ & $1.00 \mathrm{E}-03$ & $4.00 \mathrm{E}-02$ & $3.00 \mathrm{E}-01$ & $7.00 \mathrm{E}-01$ & $4.60 \mathrm{E}-02$ & $2.00 \mathrm{E}-02$ & $3.00 \mathrm{E}-03$ \\
\hline & Inhalation & $3.52 \mathrm{E}-03$ & $1.00 \mathrm{E}-03$ & & $3.00 \mathrm{E}-01$ & $7.00 \mathrm{E}-05$ & & $2.06 \mathrm{E}-02$ & $2.86 \mathrm{E}-05$ \\
\hline & Dermal & $5.25 \mathrm{E}-04$ & $1.00 \mathrm{E}-05$ & $1.20 \mathrm{E}-02$ & $6.00 \mathrm{E}-01$ & $7.00 \mathrm{E}-05$ & $4.00 \mathrm{E}-02$ & $5.40 \mathrm{E}-03$ & $6.00 \mathrm{E}-05$ \\
\hline $\mathrm{HQ}_{\text {ing }}($ Child $)$ & & $3.87 \mathrm{E}-02$ & $1.83 \mathrm{E}-03$ & $8.44 \mathrm{E}-03$ & $2.44 \mathrm{E}-03$ & $9.73 \mathrm{E}-01$ & $1.05 \mathrm{E}-01$ & $7.69 \mathrm{E}-03$ & $1.03 \mathrm{E}-01$ \\
\hline $\mathrm{HQ}_{\text {ing }}$ (Adult) & & $4.15 \mathrm{E}-03$ & $1.96 \mathrm{E}-04$ & 9.04E-04 & $2.61 \mathrm{E}-04$ & $1.04 \mathrm{E}-01$ & 1.12E-02 & $8.24 \mathrm{E}-04$ & $1.10 \mathrm{E}-02$ \\
\hline $\mathrm{HQ}_{\text {inh }}$ (Child) & & $1.08 \mathrm{E}-06$ & $5.11 \mathrm{E}-08$ & & $6.82 \mathrm{E}-08$ & $2.72 \mathrm{E}-01$ & & $2.09 \mathrm{E}-07$ & $3.01 \mathrm{E}-04$ \\
\hline $\mathrm{HQ}_{\text {inh }}$ (Adult) & & $6.07 \mathrm{E}-07$ & $2.88 \mathrm{E}-08$ & & $3.84 \mathrm{E}-08$ & $1.53 \mathrm{E}-01$ & & $1.18 \mathrm{E}-07$ & $1.70 \mathrm{E}-04$ \\
\hline $\mathrm{HQ}_{\text {derm }}$ (Child) & & $7.23 \mathrm{E}-04$ & $5.12 \mathrm{E}-04$ & $7.87 \mathrm{E}-05$ & $3.42 \mathrm{E}-06$ & $2.73 \mathrm{E}+01$ & $3.38 \mathrm{E}-04$ & $7.97 \mathrm{E}-05$ & $1.44 \mathrm{E}-02$ \\
\hline $\mathrm{HQ}_{\text {derm }}$ (Adult) & & $1.10 \mathrm{E}-04$ & $7.81 \mathrm{E}-05$ & $1.20 \mathrm{E}-05$ & $5.21 \mathrm{E}-07$ & $4.16 \mathrm{E}+00$ & $5.16 \mathrm{E}-05$ & $1.22 \mathrm{E}-05$ & $2.20 \mathrm{E}-03$ \\
\hline HI (Child) & & $3.95 \mathrm{E}-02$ & $2.34 \mathrm{E}-03$ & $8.52 \mathrm{E}-03$ & $2.44 \mathrm{E}-03$ & $2.85 \mathrm{E}+01$ & $1.05 \mathrm{E}-01$ & $7.77 \mathrm{E}-03$ & $1.17 \mathrm{E}-01$ \\
\hline$\sum \mathrm{HI}$ (Child) & & & & & 2.88 & $E+01$ & & & \\
\hline HI (Adult) & & $4.26 \mathrm{E}-03$ & $2.74 \mathrm{E}-04$ & $9.16 \mathrm{E}-04$ & $2.62 \mathrm{E}-04$ & $4.42 \mathrm{E}+00$ & $1.13 \mathrm{E}-02$ & $8.36 \mathrm{E}-04$ & $1.34 \mathrm{E}-02$ \\
\hline$\sum$ HI (Adult) & & & & & & $E+00$ & & & \\
\hline
\end{tabular}

\section{$479 \quad 3.4 .2$ Carcinogenic risk (CR)}

480 The $\mathrm{CR}$ for $\mathrm{Pb}$ was assessed through ingestion and dermal mode, and the inhalation mode was used for $\mathrm{Pb}, \mathrm{Cd}$,

$481 \mathrm{Ni}$ and $\mathrm{Cr}$ (Table 4). Note that the risk of dermal exposure to the soil is 100 times lower than the ingestion and

482 inhalation exposure (Gržetić and Ahmed Ghariani, 2008). Slope factor and soil exposures were used to calculate

483 the health risk assessment (Alfaro et al., 2015; Gbadamosi et al., 2018; Johnbull et al., 2019). The result from

484 Table 4 showed that the $\mathrm{CR}_{\text {dermal }}$ value of $\mathrm{Pb}$ for adults and children in the three districts was significantly lower,

485 means less effective of CR (Baltas et al., 2020). CR values of ingestion, inhalation and dermal exposure, and

486 integrated $\mathrm{CR}$ value $(\Sigma \mathrm{CR})$ of all carcinogenic metals for children and adults were lower than the acceptance

487 tolerance risk, $10^{-6}-10^{-4}$. However, CR values of our results for ingestion purpose were comparatively more than

488 inhalation and dermal exposure. Since $\mathrm{Fe}, \mathrm{Mn}, \mathrm{Cu}$ and $\mathrm{Zn}$ are not human carcinogens, these metals were not 489 considered for assessment of CR, (Gbadamosi et al., 2018; Gržetić and Ahmed Ghariani, 2008; Johnbull et al.,

490 2019). The obtained results of the potential carcinogenic risks for adults and children via the exposure to heavy

491 metals in CHT soils show a very insignificant value. 
492 Table 4. Carcinogenic risks of the metal elements in the soil to children to adult.

\begin{tabular}{|c|c|c|c|c|c|c|c|}
\hline \multicolumn{8}{|c|}{ Carcinogenic Risk Assessment } \\
\hline \multirow[t]{2}{*}{ Metal } & \multirow[t]{2}{*}{ Slope factor } & \multicolumn{3}{|c|}{ Child } & \multicolumn{3}{|c|}{ Adult } \\
\hline & & $\mathrm{Rm}$ & Kc & $\mathrm{Bb}$ & $\mathrm{Rm}$ & Kc & $\mathrm{Bb}$ \\
\hline \multicolumn{8}{|c|}{ CR for Ingestion } \\
\hline $\mathrm{Pb}$ & $8.50 \mathrm{E}-03$ & $1.01 \mathrm{E}-07$ & $6.72 \mathrm{E}-08$ & $1.28 \mathrm{E}-07$ & 4.35E-08 & $2.88 \mathrm{E}-08$ & $5.47 \mathrm{E}-08$ \\
\hline \multicolumn{8}{|c|}{ CR for Inhalation } \\
\hline $\mathrm{Pb}$ & 4.20E-02 & $1.40 \mathrm{E}-11$ & $9.28 \mathrm{E}-12$ & $1.76 \mathrm{E}-11$ & $3.16 \mathrm{E}-11$ & 2.09E-11 & 3.97E-11 \\
\hline $\mathrm{Cd}$ & $6.30 \mathrm{E}+00$ & $2.81 \mathrm{E}-11$ & $2.49 \mathrm{E}-11$ & 2.97E-11 & $6.33 \mathrm{E}-11$ & $5.63 \mathrm{E}-11$ & 6.71E-11 \\
\hline $\mathrm{Ni}$ & $8.40 \mathrm{E}-01$ & $3.06 \mathrm{E}-10$ & $1.89 \mathrm{E}-10$ & 4.33E-10 & $6.68 \mathrm{E}-10$ & 4.26E-10 & $9.76 \mathrm{E}-10$ \\
\hline $\mathrm{Cr}$ & 4.10E-01 & $2.25 \mathrm{E}-10$ & $3.22 \mathrm{E}-10$ & $3.60 \mathrm{E}-10$ & $5.08 \mathrm{E}-10$ & 7.27E-10 & 8.12E-10 \\
\hline \multicolumn{8}{|c|}{ CR for dermal } \\
\hline $\mathrm{Pb}$ & $8.50 \mathrm{E}-06^{*}$ & $2.48 \mathrm{E}-15$ & $1.64 \mathrm{E}-15$ & $3.12 \mathrm{E}-15$ & $7.96 \mathrm{E}-16$ & $5.28 \mathrm{E}-16$ & $1.00 \mathrm{E}-15$ \\
\hline$\sum \mathrm{CR}$ & & $1.02 \mathrm{E}-07$ & $6.77 \mathrm{E}-08$ & $1.28 \mathrm{E}-07$ & 4.47E-08 & $3 \mathrm{E}-08$ & 5.66E-08 \\
\hline
\end{tabular}

\section{4. Conclusion}

495 Concentration of heavy metals were determined in sequence of $\mathrm{Fe}>\mathrm{Mn}>\mathrm{Zn}>\mathrm{Cu}>\mathrm{Cr}>\mathrm{Ni}>\mathrm{Pb}>\mathrm{Cd}$ in soils 496 of 37 sites collected from Chittagong Hill Tracts area, Bangladesh. Essential elements (Fe, Mn and Zn) show 497 relatively greater value than the toxic $(\mathrm{Pb}, \mathrm{Cd}, \mathrm{Cu})$ metals. $\mathrm{Pb}, \mathrm{Cd}, \mathrm{Cu}$ and $\mathrm{Zn}$ indicated significant enrichment 498 with $\mathrm{EF}>1$ in the soil of Rm-3, Kc-14 sites. Fe showed significant contamination in soil (CF>1) in most of the 499 analyzed sites. PLI <1 was found almost in all sites which expressed the acceptability of soil quality except Bb-5 500 site. The potential ecological risk factor of Cd was shown a considerable ecological risk. PERI values indicated a 501 moderate ecological risk, whereas, among three districts, a considerable ecological risk exists in Bandarban.

502 This study reveals that there is no adverse carcinogenic health risk via the use of CHT soils. However, there is a 503 possible non-carcinogenic risk for both adults and children by the three exposure pathway from iron. Hence, 504 regular monitoring is needed for the documentation of any alternation in the quality of soil and minimise the 505 outbreak of health disorders and damage to the forest ecosystem. It is presumed that some of the main causes of 506 soil pollution in CHT are shifting cultivation, clearing and burning of jungles. Other heavy metals (As, Co, Hg, 507 etc.) as well as other parameters such as organic content, total organic carbon, oxygen demand and moisture 508 content etc. may be considered for further analysis.

\section{Declarations}

\section{Ethics approval and consent to participate}

512 Not applicable

\section{Consent for publication}

514 Not applicable

\section{Availability of data and materials}

516 The datasets used and analysed during the current study are available from the corresponding author on 517 reasonable request. 
519 The authors declare that they have no competing interests in this section.

$520 \quad$ Funding

$521 \quad$ Not applicable

522 Authors' contributions

523 Troyee Barua: Conceptualization, Methodology, Data curation, Formal analysis and Writing - original draft

524 AKM Saiful Islam Bhuian : Supervision

525 Mayeen Uddin Khandaker: Writing - review and editing of the manuscript

526 Md. Abdur Rashid: Validation, Supervision

527 Nipa Deb: Software

528 Shahadat Hossain: Formal analysis

\section{Acknowledgements}

531 Cooperation from the staffs of the AEC, Chattogram is greatly acknowledged. The authors would like to thank Mr. Soumik Barua for software analysis and support during the collection of soil.

\section{References}

Abdulqaderismaeel, W., Kusag, A., 2015. Enrichment Factor and Geo-accumulation Index for Heavy Metals at Industrial Zone in Iraq. IOSR J. Appl. Geol. Geophys. Ver. I 3, 2321-990. https://doi.org/10.9790/099003312632

Afzal, M., Shabir, G., Iqbal, S., Mustafa, T., Khan, Q.M., Khalid, Z.M., 2014. Assessment of Heavy Metal Contamination in Soil and Groundwater at Leather Industrial Area of Kasur, Pakistan. Clean - Soil, Air, Water 42, 1133-1139. https://doi.org/10.1002/clen.201100715

Aga, B., Brhane, G., 2014. Determination The Level Of Some Heavy Metals ( Mn And Cu ) In Drinking Water Using Wet Digestion Method Of Adigrat Town. Int. J. Technol. Enhanc. Emerg. Eng. Res. 2, 32-36.

Ahammad, R., Stacey, N., 2016. Forest and agrarian change in the Chittagong Hill Tracts region of Bangladesh.

Alfaro, M.R., Montero, A., Ugarte, O.M., do Nascimento, C.W.A., de Aguiar Accioly, A.M., Biondi, C.M., da Silva, Y.J.A.B., 2015. Background concentrations and reference values for heavy metals in soils of Cuba. Environ. Monit. Assess. 187. https://doi.org/10.1007/s10661-014-4198-3

Anumalla Mahender, B. P. Mallikarjuna Swamy, A.A. and J.A., 2019. Tolerance of Iron-Deficient and -Toxic Soil Conditions in Rice.

Ayangbenro, A.S., Babalola, O.O., 2017. A new strategy for heavy metal polluted environments: A review of microbial biosorbents. Int. J. Environ. Res. Public Health 14. https://doi.org/10.3390/ijerph14010094 
Bangladesh Forest Department, 2016. Updating Forestry Master Plan for Bangladesh Bangladesh Forestry Master Plan 2017-2036 ( Draft Final ).

Barua, T., Saiful Islam Bhuian, A.K.M., Hossain, S., Deb, N., Ahmed, M., Hossain, S., Rashid, M.A.,

Khandaker, M.U., 2019. The presence of radioactive and metal contaminants in wild mushrooms grown in Chattogram hill tracts, Bangladesh. J. Radioanal. Nucl. Chem. 322, 173-182. https://doi.org/10.1007/s10967-019-06579-6

Biswas, S., Swanson, M.E., Shoaib, J.U.M., Sirajul Haque, S.M.S., 2010. Soil chemical properties under modern and traditional farming systems at Khagrachari, Chittagong Hill Tracts, Bangladesh. J. For. Res. 21, 451-456. https://doi.org/10.1007/s11676-010-0096-x

Chonokhuu, S., Batbold, C., Chuluunpurev, B., Battsengel, E., Dorjsuren, B., Byambaa, B., 2019. Contamination and health risk assessment of heavy metals in the soil of major cities in Mongolia. Int. J. Environ. Res. Public Health 16. https://doi.org/10.3390/ijerph16142552

Chrzan, A., Formicki, G., Marko-Worlowska, M., 2013. Heavy metals concentration in forest soils. Fresenius Environ. Bull. 22, 1993-1996.

Fiori, C. da S., Rodrigues, A.P. de C., Santelli, R.E., Cordeiro, R.C., Carvalheira, R.G., Araújo, P.C., Castilhos, Z.C., Bidone, E.D., 2013. Ecological risk index for aquatic pollution control: a case study of coastal water bodies from the Rio de Janeiro State, southeastern Brazil. Geochim. Bras. 27, 24-36. https://doi.org/10.5327/z0102-9800201300010003

Fonseca-Nunes, A., Jakszyn, P., Agudo, A., 2014. Iron and cancer risk-a systematic review and meta-analysis of the epidemiological evidence. Cancer Epidemiol. Biomarkers Prev. 23, 12-31. https://doi.org/10.1158/1055-9965.EPI-13-0733

Gbadamosi, M.R., Afolabi, T.A., Ogunneye, A.L., Ogunbanjo, O.O., Omotola, E.O., Kadiri, T.M., Akinsipo, O.B., Jegede, D.O., 2018. Distribution of radionuclides and heavy metals in the bituminous sand deposit in Ogun State, Nigeria - A multi-dimensional pollution, health and radiological risk assessment. J. Geochemical Explor. 190, 187-199. https://doi.org/10.1016/j.gexplo.2018.03.006

Gržetić, I., Ahmed Ghariani, R.H., 2008. Potential health risk assessment for soil heavy metal contamination in the central zone of Belgrade (Serbia). J. Serbian Chem. Soc. 73, 923-934. https://doi.org/10.2298/JSC0809923G

Hassan, Masud, Hassan, R., Pia, H., Hassan, Md., Ratna, S., Aktar, M., 2017. Variation of Soil Fertility with Human Health Risk Assessment of Heavy Metal Pollution in Industrial Affected Soils by Coal Mining and Metallurgy in Ostrava, Czech Republic.

Hernandez, L., Probst, A., Probst, J.L., Ulrich, E., 2003. Heavy metal distribution in some French forest soils: Evidence for atmospheric contamination. Sci. Total Environ. 312, 195-219. 
Hou, D., O’Connor, D., Nathanail, P., Tian, L., Ma, Y., 2017. Integrated GIS and multivariate statistical analysis for regional scale assessment of heavy metal soil contamination: A critical review. Environ. Pollut. 231, 1188-1200. https://doi.org/10.1016/j.envpol.2017.07.021

Huang, L., Rad, S., Xu, L., Gui, L., Song, X., Li, Y., Wu, Z., Chen, Z., 2020. Heavy Metals Distribution, Sources, and Ecological Risk Assessment in Huixian Wetland, South China. Water 12, 1-14.

Jia, Z., Li, S., Wang, L., 2018. Assessment of soil heavy metals for eco-environment and human health in a rapidly urbanization area of the upper Yangtze Basin. Sci. Rep. 8, 1-14. https://doi.org/10.1038/s41598018-21569-6

Johnbull, O., Abbassi, B., Zytner, R.G., 2019. Risk assessment of heavy metals in soil based on the geographic information system-kriging technique in Anka, Nigeria. Environ. Eng. Res. 24, 150-158.

601

602 https://doi.org/10.4491/eer.2018.130

603

Kacholi, D.S., Sahu, M., 2018. Levels and Health Risk Assessment of Heavy Metals in Soil, Water, and

604

605

Khandaker, M.U., Asaduzzaman, K., Nawi, S.M., Usman, A.R., Amin, Y.M., Daar, E., Bradley, D.A., Ahmed,

606 H., Okhunov, A.A., 2015. Assessment of radiation and heavy metals risk due to the dietary intake of marine fishes (Rastrelliger kanagurta) from the Straits of Malacca. PLoS One 10, 1-16. https://doi.org/10.1371/journal.pone.0128790

Kobierski, M., Dabkowska-Naskret, H., 2012. Local Background Concentration of Heavy Metals in Various

Svoboda L, Chrastny V.. Contents of eight trace elements in edible mushrooms from a rural area. Food Additives and Contaminants, 2007, 25 (01), pp.51-58. ff10.1080/02652030701458519ff. ffhal-00577280

Material, S., 2017. Evaluation of Wet Digestion Methods for Quantification of Metal Content in Electronic. https://doi.org/10.3390/resources6040064

Miah, S., Dey, S., Sirajul Haque, S.M., 2010. Shifting cultivation effects on soil fungi and bacterial population in Chittagong Hill Tracts, Bangladesh. J. For. Res. 21, 311-318. https://doi.org/10.1007/s11676-0100076-1

Muzerengi, C., 2017. Enrichment and Geoaccumulation of Pb , Zn , As , Cd and Cr in soils near New Union 620 Osman, K.T., 2014. Fertility Status of some forested soils of Chittagong Hill Tracts, Bangladesh.

621 Pandey, B., Agrawal, M., Singh, S., 2016. Ecological risk assessment of soil contamination by trace elements 622 around coal mining area. J. Soils Sediments 16, 159-168. https://doi.org/10.1007/s11368-015-1173-8 623 Pejman, A., Bidhendi, G., Ardesani, M., Saeedi, M., Baghvand, A., 2015. A new index for assessing heavy 624 metals contamination in sediments: A case study. Ecol. Indic. 58, 365-373. 
Perkin Elmer, 1996. Analytical Methods for Atomic Absorption Spectroscopy. Anal. Methods At. Absorpt. Spectrosc. 216.

Perković, I., Lazić, A., Pernar, N., Roje, V., Bakšić, D., 2017. Forest soil pollution with heavy metals (Pb, Zn, $\mathrm{Cd}$, and $\mathrm{Cu}$ ) in the area of the "French Mines" on the Medvednica Mountain, Republic of Croatia. SouthEast Eur. For. 8, 31-40. https://doi.org/10.15177/seefor.17-08

Rademacher, P., 2001. Atmospheric heavy metals and forest ecosystems. Fed. Res. For. For. Prod. 19pp.

Rastegari Mehr, M., Keshavarzi, B., Moore, F., Sharifi, R., Lahijanzadeh, A., Kermani, M., 2017. Distribution, source identification and health risk assessment of soil heavy metals in urban areas of Isfahan province, Iran. J. African Earth Sci. 132, 16-26. https://doi.org/10.1016/j.jafrearsci.2017.04.026

Sana 'a Odat, 2013. Calculating Pollution Indices of Heavy Metal along Irbid/Zarqa Highway-Jordan. Technol. Int. J. Appl. Sci. 8, 72-76.

Širić, I., Humar, M., Kasap, A., Kos, I., Mioč, B., Pohleven, F., 2016. Heavy metal bioaccumulation by wild edible saprophytic and ectomycorrhizal mushrooms. Environ. Sci. Pollut. Res. 23, 18239-18252. https://doi.org/10.1007/s11356-016-7027-0

Stihi, C., Radulescu, C., Busuioc, G., Popescu, I.V., Gheboianu, A., Ene, A., 2011. Studies on accumulation of heavy metals from substrate to edible wild mushrooms. Rom. Reports Phys. 56.

UNICEF Bangladesh, 2019. Many Tracts One Community.

US EPA, 2011. Exposure Factors Handbook: 2011 edition.

Wahab, M.I.A., Razak, W.M.A.A., Sahani, M., Khan, M.F., 2020. Characteristics and health effect of heavy metals on non-exhaust road dusts in Kuala Lumpur. Sci. Total Environ. 703, 135535. https://doi.org/10.1016/j.scitotenv.2019.135535

Wang, A. jun, Kawser, A., Xu, Y. hang, Ye, X., Rani, S., Chen, K. liang, 2016. Heavy metal accumulation during the last 30 years in the Karnaphuli River estuary, Chittagong, Bangladesh. Springerplus 5, 1-14. https://doi.org/10.1186/s40064-016-3749-1

Weissmannová, H.D., Miho, S., Chovanec, P., 2019. Potential Ecological Risk and Human Health Risk Assessment of Heavy Metal Pollution in Industrial Affected Soils by Coal Mining and Metallurgy in Ostrava , Czech Republic 16(22):449. https://doi.org/10.3390/ijerph16224495

Wild Thurst of Bangladesh, 2010. Baseline survey of Bears in Bangladesh.

Zhang, W., 2016. A review on heavy metal contamination in the soil worldwide : Situation, impact and remediation techniques.

Zinkute, R., Taraškevičius, R., Jankauskaitè, M., Stankevičius, Ž., 2017. Methodological alternatives for calculation of enrichment factors used for assessment of topsoil contamination. J. Soils Sediments 17, 440-452. https://doi.org/10.1007/s11368-016-1549-4 
660 identify the homogeneous desertification management units. PLoS One 14, 1-21.

$661 \quad$ https://doi.org/10.1371/journal.pone.0226355 
Figures

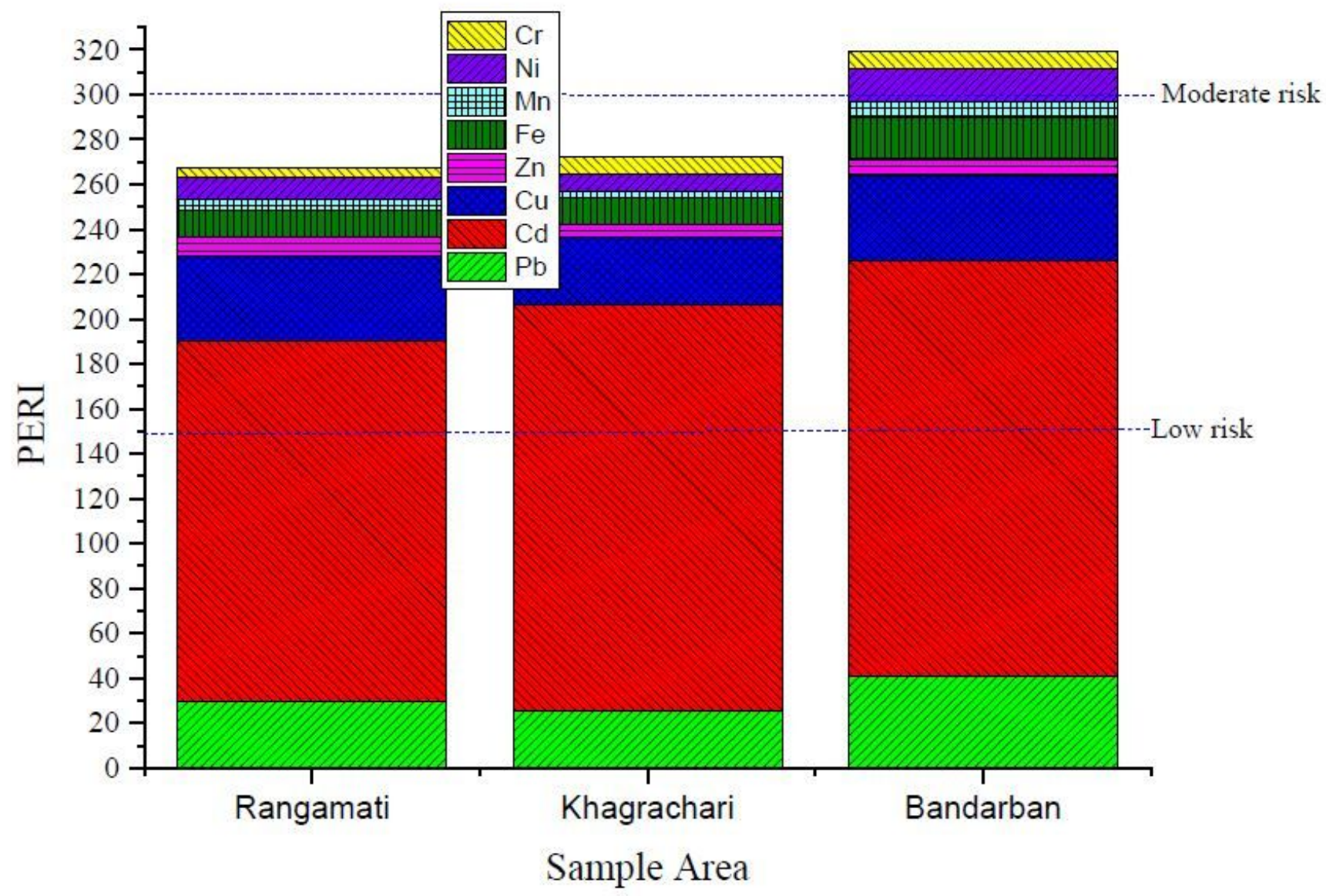

Figure 1

Potential ecological risk indices (PERI) in the soil of $\mathrm{CHT}$. 


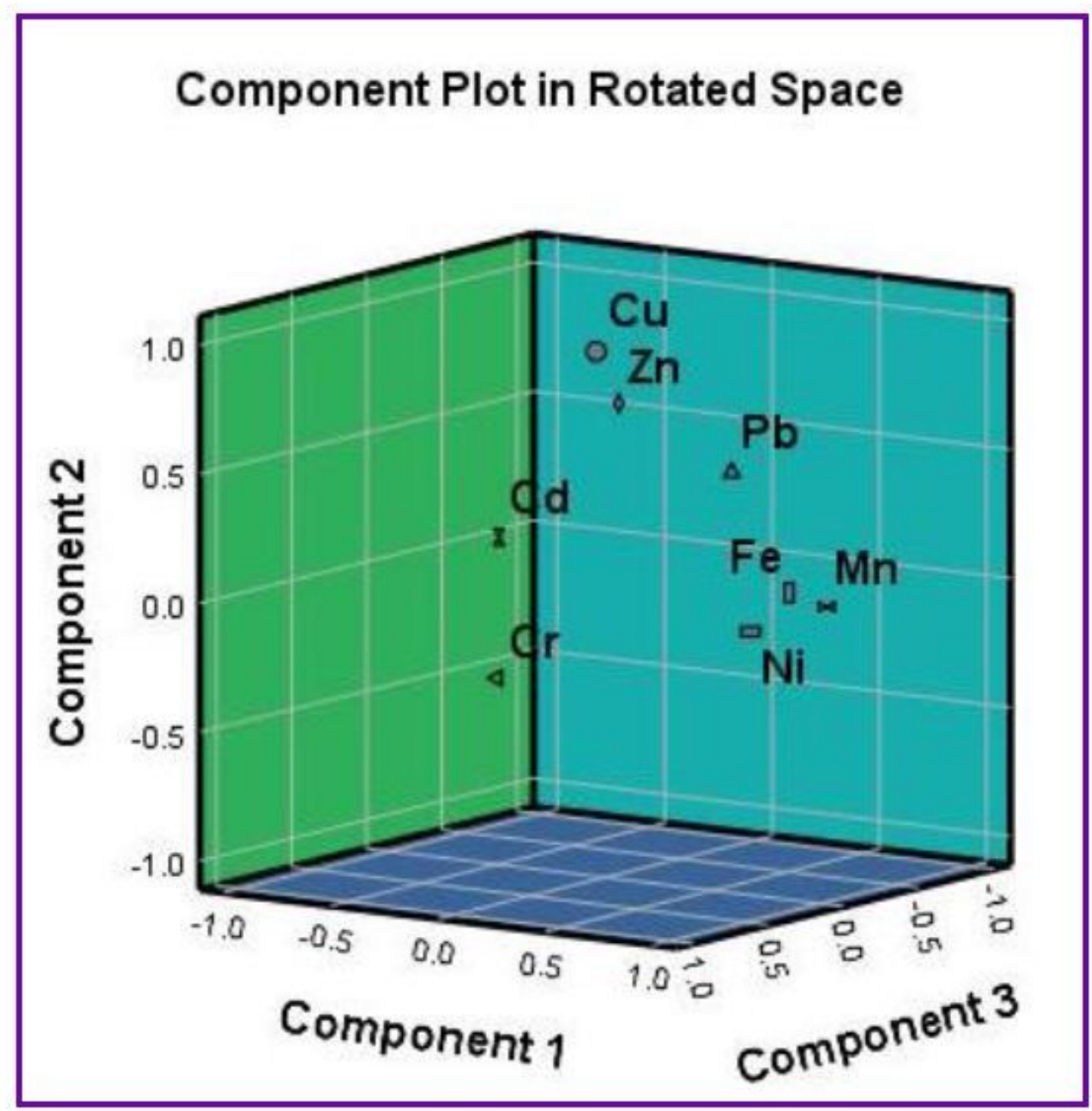

Figure 2

PCA loading plot of studied heavy metals in rotated space. 


\section{Dendrogram using Ward Linkage}

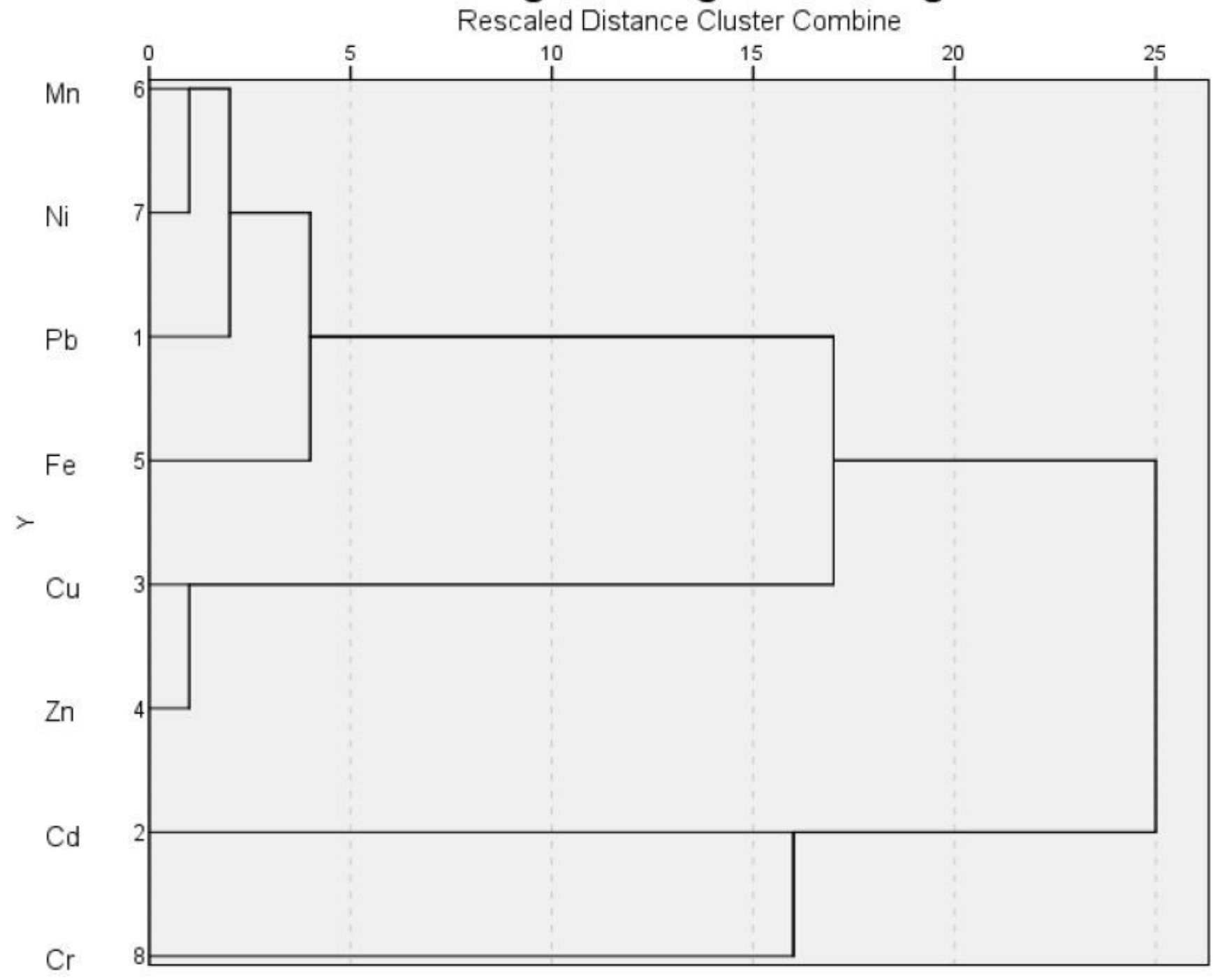

Figure 3

Dendrogram showing hierarchical cluster analysis of analyzed metals of the studied area. 